\title{
A Computational Descriptor Analysis on Excited State Behaviours of a Series of TADF and Non-TADF Compounds
}

\author{
Pelin Ulukan, ${ }^{a}$ Ekin Esme Bas, ${ }^{a}$ Rengin Busra Ozek, ${ }^{a}$ Cansul Dal Kaynak, ${ }^{a}$ Antonio Monari,,${ }^{b, c}$ Viktorya Aviyente*,a and \\ Saron Catak ${ }^{*}$ a \\ aDepartment of Chemistry, Bogazici University, Bebek, 34342 Istanbul, Turkey \\ bUniversité de Lorraine and CNRS, LPCT UMR 7019, F-54000 Nancy, France \\ 'Université de Paris and CNRS, Itodys, F-75006 Paris, France.
}

\begin{abstract}
The thermally activated delayed fluorescence (TADF) behaviours of seventeen organic TADF emitters and two non-TADF chromophores bearing various donor and acceptor moieties were investigated, focusing on their torsion angles, singlet-triplet gap $\left(\Delta \mathrm{E}_{S T}\right)$, spin orbit couplings (SOC) and topological $\Phi_{S}$ index. Electronic structure calculations were performed in the framework of the Tamm-Dancoff approximation (TDA) allowing to characterize reverse intersystem crossing (RISC) probability between the $S_{1}$ and $\mathrm{T}_{1}$ states. In addition, experimental $\Delta \mathrm{E}_{\mathrm{ST}}$ data were taken into account to choose the most appropriate functional and basis set, while absorption spectra were obtained by considering vibrational and dynamical effects through a Wigner sampling of the ground state equilibrium regions. Examining all the parameters obtained in our computational study, we

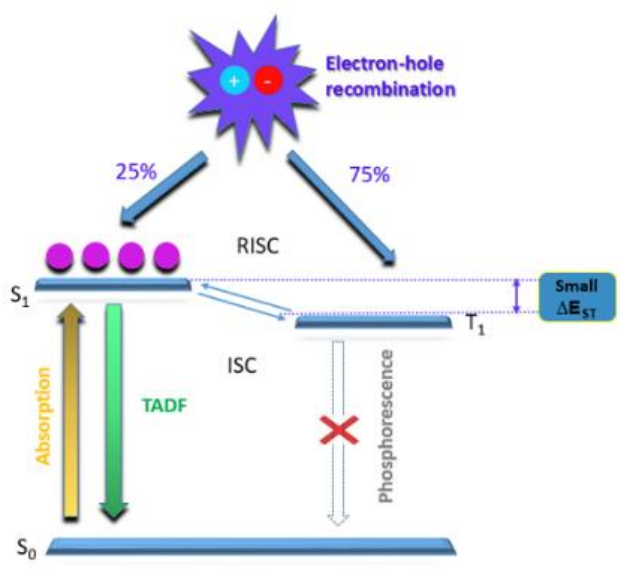
rationalized the influence of electron-donating and electron-accepting groups and the effects of geometrical factors, namely torsion angles, on a wide class of diverse compounds ultimately providing an easy and computationally effective protocol to assess TADF efficiencies.
\end{abstract}

\section{Introduction}

Since the original proposal of Organic Light-Emitting Diodes (OLEDs) by Tank and Van Slyke in 1987, ${ }^{1}$ significant progress has been made for their development and application in different technologies, including display apparatus. OLEDs represent an important innovation in lighting markets, providing improved image quality, high brightness, low fabrication costs, low power consumption and high durability. ${ }^{2,3}$ They operate based on the physical phenomenon known as electroluminescence (EL), i.e. the conversion of electrical energy into light. ${ }^{4}$ In OLEDs, EL is achieved by fluorescent materials, which undergo a two-step process, an initial absorption leading to the population of an electronically excited state and a subsequent radiative decay to the electronic ground state, which is known as prompt fluorescence. ${ }^{2}$ However, despite possessing useful properties, several drawbacks still limit the development of OLEDs, notably related to technical issues, such as high-power consumption, insufficient device efficiency and high driving voltage. Insufficient device efficiencies in OLEDs, has led to the use of high quantum yield phosphorescent materials utilizing alternative routes to achieve radiative decay. These are based on intersystem crossing (ISC), and hence the population of triplet states, leading to phosphorescence. ${ }^{5}$ The exploitation of both singlet and triplet excited states has led to an increase in internal quantum efficiencies (IQE) up to $100 \%$. Although the use of phosphorescent materials significantly raised quantum efficiencies in OLEDs, the use of heavy metals, such as Ir or Pt, limited their application due to increased device costs and environmental pollution. Moreover, the lack of stability is an additional drawback of phosphorescent OLEDs (PhOLEDs). Indeed, chemical degradation leading to charge traps, non-radiative recombination sites, and luminance loss, are serious issues affecting PhOLEDs. ${ }^{5}$ In the quest to increase OLED efficiencies, thermally activated delayed fluorescence (TADF) materials have attracted great attention as they lead to the population of both singlet and triplet states without using any heavy metals (Figure 1 )..$^{6-12}$ 

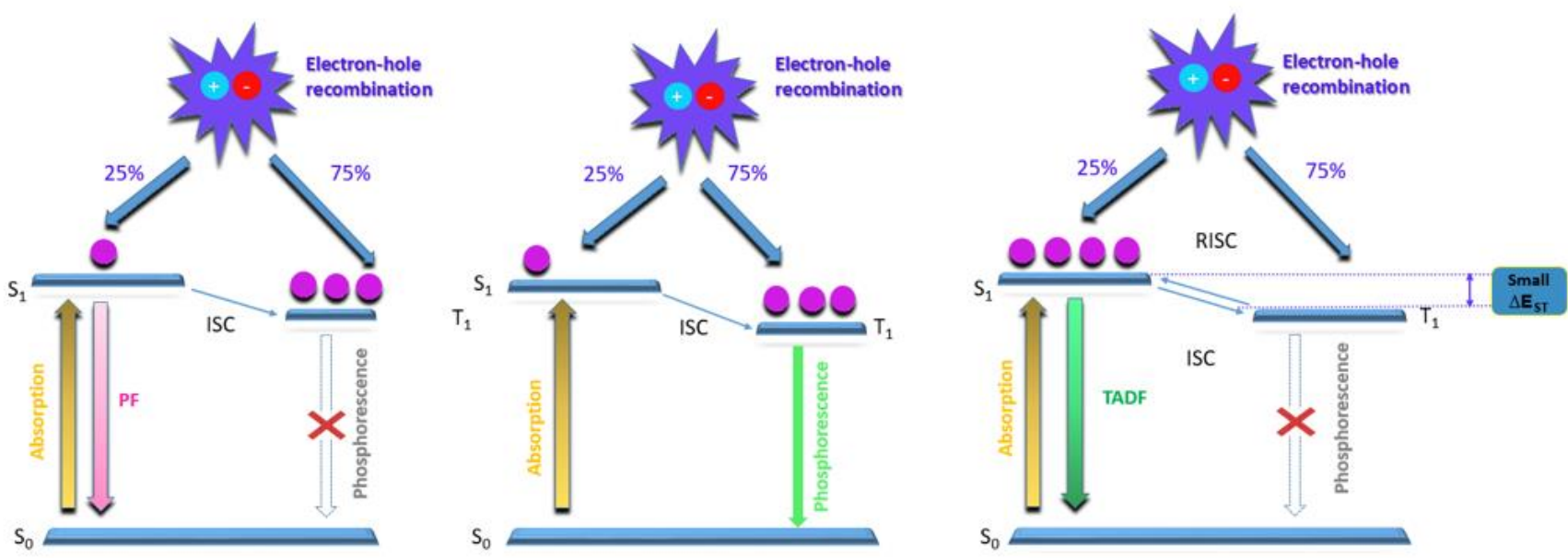

Figure 1. Jablonski diagram for OLED, PHOLED and TADF materials, respectively.

Soon after the first organic TADF emitter was reported in 2011, studies related to TADF based OLEDs gained momentum and nowadays, external quantum efficiencies (EQE) reaching up to $30 \%$ together with internal quantum efficiencies (IQE) of $100 \%$ have been reported. ${ }^{13}$ In addition to their applications in OLEDs, TADF materials also have applications in fluorescence lifetime imaging, ${ }^{14}$ and oxygen sensing. ${ }^{15-16}$

TADF materials also possess the critical advantage of enabling different color emission ${ }^{20-34}$ and serving as host materials in emission layers. ${ }^{30}$ Emission, which may span from blue to red, is mainly controlled by the degree of intramolecular charge transfer (ICT) of the involved excited states. $^{31-32}$ Since ICT is one of the most important parameters in TADF activity, numerous design strategies were attempted to enhance this fundamental process. One strategy involves the use of donor-acceptor (D-A), D- $\pi-A, D-\pi-A-\pi-D$ molecular frameworks, in which the highest occupied molecular orbitals (HOMO) and lowest unoccupied molecular orbital (LUMO) are localized on donor and acceptor units, respectively, hence leading to spatially separated frontier orbitals. ${ }^{33}$ Various donor and acceptor groups were designed to enhance charge transfer in TADF luminophores. The most frequently used donor moieties are diphenylamine, , $^{2,34,35}$ carbazole, ${ }^{23,36-44}$ acridine, ${ }^{17,20,45}$ and phenoxazine derivatives, ${ }^{46-49}$ while the most common acceptor units include boron, ${ }^{50-58}$ sulfone, $23,25,41$ and benzophenone derivatives (Figure 2). ${ }^{20,24,59,60}$ However, TADF systems are not limited to these building blocks, other interesting frameworks were designed such as cyanobenzenes, ${ }^{59}$ triazines, ${ }^{61}$ oxadiazoles, ${ }^{31}$ sulfones, ${ }^{62}$ and spiro derivatives. ${ }^{63,64}$

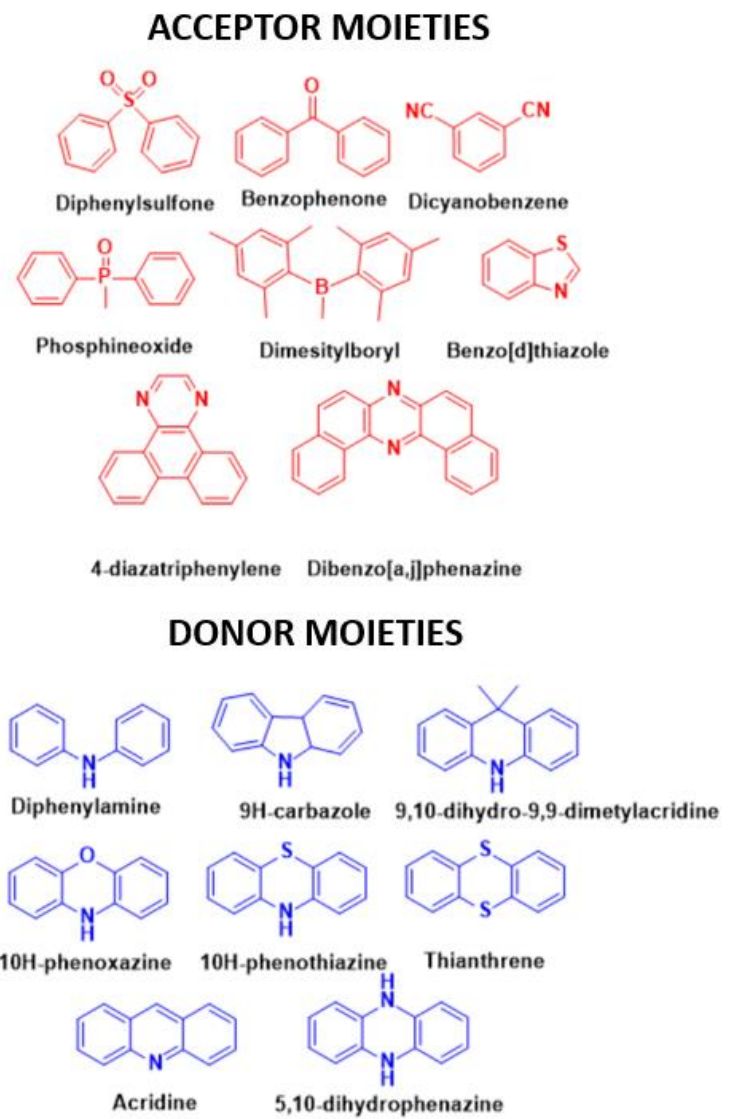

Figure 2. Commonly used acceptor (red) and donor (blue) moieties in TADF molecules. ${ }^{65}$

From a photophysical point of view, TADF is based on the upconversion from the triplet $\left(T_{1}\right)$ to the singlet $\left(S_{1}\right)$ state, which is only possible if $\Delta \mathrm{E}_{S \mathrm{~T}}$ is sufficiently small, i.e. less than $0.1 \mathrm{eV}$. Such an energetic alignment facilitates the reverse intersystem crossing process (RISC), also known as, upintersystem crossing process (UISC). ${ }^{66}$ Although TADF compounds with $\Delta E_{\mathrm{ST}}$ values smaller than $0.1 \mathrm{eV}$ show the best performances, some fluorophores with $\Delta E_{S T}$ values close to $0.5 \mathrm{eV}$ exhibit TADF emission. Moreover, rigid molecular 
architectures are preferred over flexible ones for high performance TADF devices, since they minimize non-radiative decay due to vibrational and rotational motions. ${ }^{67}$ In addition to a small $\Delta \mathrm{E}_{\mathrm{ST}}$ gap, the electronic coupling between a charge transfer singlet $\left({ }^{1} \mathrm{CT}\right)$ and a local triplet $\left({ }^{3} \mathrm{LE}\right)$ state strongly influences TADF efficiency. ${ }^{68}$ Indeed, the amount of spin orbit coupling is crucial to determine RISC efficiency and ultimately delayed fluorescence. ${ }^{69}$

The rate for RISC ( $k_{\text {RISC }}$ ) is usually expressed combining Fermi's Golden Rule with Marcus' Theory, ${ }^{70}$ as:

$$
\begin{gathered}
k_{\mathrm{RISC}}=\frac{2 \pi}{\hbar}\left|H_{\mathrm{SO}}\right|^{2}\left(4 \pi \lambda k_{\mathrm{B}} T\right)^{-\frac{1}{2}} \exp \left(\frac{-E_{\mathrm{A}}}{k_{\mathrm{B}} T}\right) \\
E_{A}=\frac{\left(\Delta E_{\mathrm{ST}}+\lambda\right)^{2}}{4 \lambda}
\end{gathered}
$$

The key parameters being the reorganization energy $\lambda$, the SOC coupling $\mathrm{H}_{\mathrm{so}}$, and $\mathrm{E}_{\mathrm{a}}$ which is related to the energy gap $\Delta E_{\mathrm{ST}}$ through Equation 2.

The amount of CT $\left(q^{\mathrm{CT}}\right)$ and the effective CT distance $\left(d^{\mathrm{CT}}\right)$ for ground and excited states have also been used to assess TADF performance computationally. ${ }^{71}$ The $\mathrm{CT}$ character of $\mathrm{T}_{1}$ states has also been analyzed through the quantification of the excited state dipole moments. ${ }^{72}$ Furthermore, environmental factors are also important in dictating the overall TADF efficiency, in particular the ISC rates, as shown by the sensitivity to solvent. ${ }^{66}$

In addition, as Yu-Zhong Xie and co-workers reported, minimum energy crossing points (MECP) between $S_{1}$ and $T_{1}$ states are crucial, since they represent funneling regions, allowing the non-adiabatic transition between different electronic states. ${ }^{73}$

In this study, we propose a new computational strategy based on rational material designs, investigating the relationship between molecular structures and photophysical properties of a wide range of emitters by means of $a b$ initio calculations. To understand the correlation between the molecular structure and TADF properties, a comparative study is performed along molecules that possess TADF features and compounds known to be poor TADF emitters (henceforth, they will be referred to as non-TADF molecules). Indeed, a systematic study on the relation between structural, electronic properties, and the TADF efficiency of different classes of compounds is somehow missing. We plan to bridge this gap by using molecular modelling and simulation to provide a unified description of the different parameters related to TADF performance.

For this purpose, ground state structural properties, such as the torsional angles, are explored and related to the optical properties and the singlet-triplet gap. Our analysis of different excited state descriptors, including singlet-triplet gap, SOC magnitude, and the amount of charge transfer provides a useful and computationally effective protocol to rationalize TADF efficiency. More specifically, the combined effect of $\Delta E_{\mathrm{ST}}$ and SOC on the (R)ISC probability $\chi$ can be expressed as: ${ }^{70}$

$$
\chi \propto \frac{\mathrm{H}_{\mathrm{SO}}}{\Delta \mathrm{E}_{\mathrm{ST}}}
$$

As seen in Equation 3, although the RISC probability decreases with the increase in $\Delta E_{\mathrm{ST}}, H_{\mathrm{SO}}$ which competes with $\Delta E_{\mathrm{ST}}$, albeit being usually overlooked, may play a significant role and hence, should be properly accounted for to sketch useful design rules for TADF compounds.

\section{Computational Methodology}

Prior to the evaluation of all photophysical properties, a conformational analysis was performed using the Gaussian 16 software package ${ }^{74}$ to characterize all possible conformers of model TADF and non-TADF molecules. Density Functional Theory (DFT) calculations with the M06-2X ${ }^{75,76}$ meta-hybrid functional and the $6-31+G(d, p)^{77,78}$ basis set have been carried out to optimize the ground state conformers and the corresponding $T_{1}$ geometries of model compounds. This choice is justified by the good performance of M06-2X in reproducing the ground-state geometries of aromatic compounds. ${ }^{79}$ Since the conformational variability is not related to the light-active core, all conformers have the same TDA properties because these properties are mainly affected by the twisting angle between donor and acceptor moieties or between the donor and bridge moieties. In recent literature, this behavior of TADF molecules has been proven by the comparison of TDA properties from Boltzmann Distribution of different conformers and the properties of the lowest energy conformer. ${ }^{80}$ Thus, we continue further analysis considering, only the lowest energy conformers of each molecule (see Tables S1-S5). The energy and nature of excited states are assessed at the $B 3 L Y P^{81} / 6-31+G(d, p), M 06-2 X / 6-31+G(d, p)$, CAM-B3LYP $82 / 6-31+G(d, p)$, ${ }^{2} B 97 X D^{83} / 6-31+G(d, p)$ levels of theory, $6-311++G(3 d f, 3 p d)^{84}$ and $6-311++G(2 d, 2 p)^{85}$ basis sets were used, in all calculations, for sulfur and phosphorus atoms, respectively. A series of benchmark calculations with Becke's hybrid B3LYP functional and $6-31+G(d, p)$ and 6$311+G(d, p)$ basis sets are also performed. From our benchmark, it was clearly observed that increasing the basis set does not induce any noticeable change on the calculated absorption spectra (see Tables S6-S7).

Integral equation formalism polarizable continuum model (IEF-PCM) is used in all calculations, ${ }^{86}$ to implicitly model the solvent environment. Optimized geometries were rendered with CYLview software package. ${ }^{87}$ 


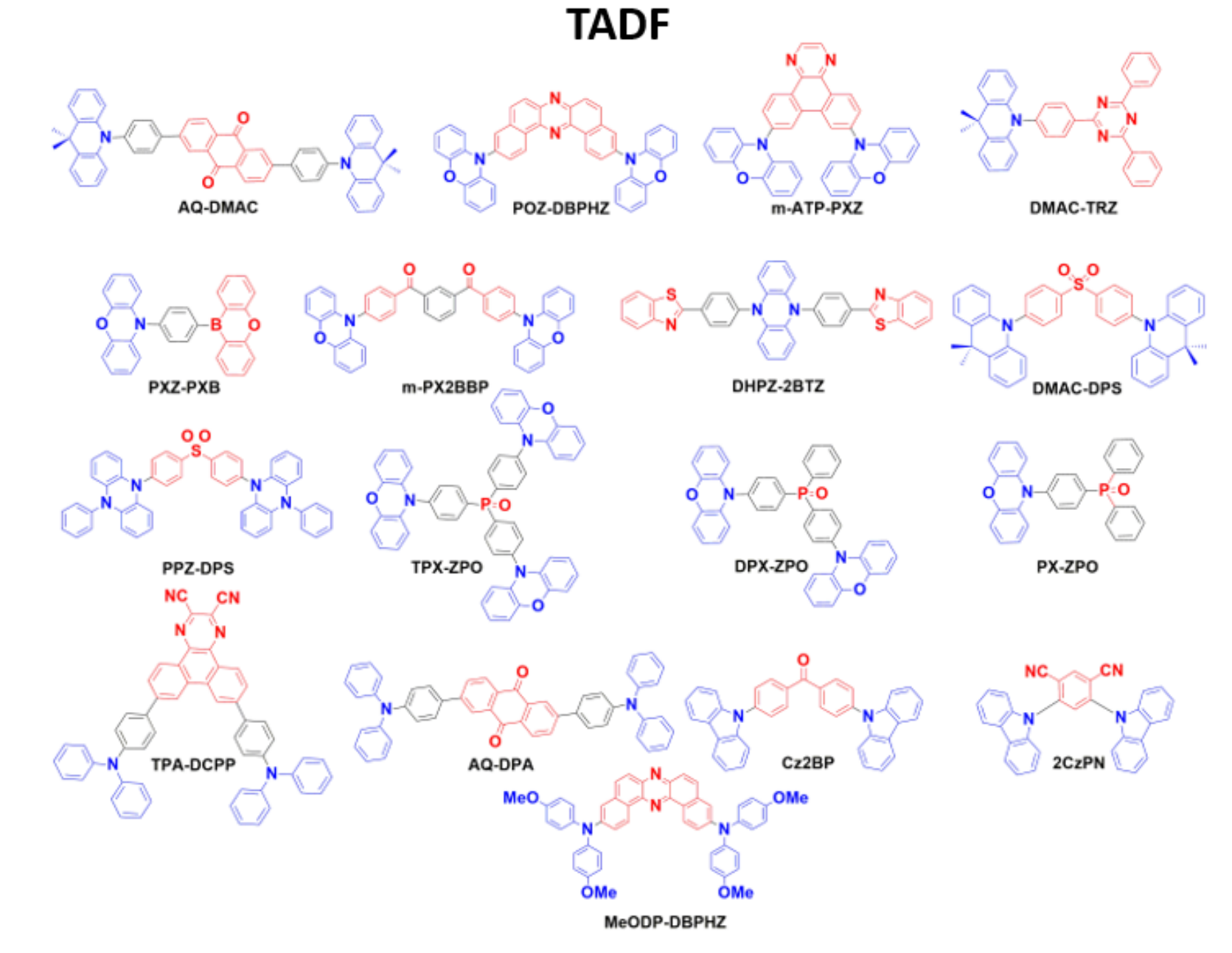

NON-TADF

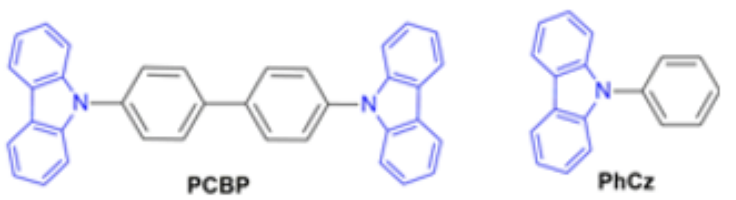

Figure 3. TADF and non-TADF molecules investigated in this study

Tamm Dancoff Approximation (TDA) was employed for all the excited state calculations. This choice is due to the fact that the TDA method provides a more balanced description of both triplet and singlet excited states, and compared to TimeDependent DFT (TD-DFT) is free from triplet instability issues. ${ }^{88}$ All excited state calculations have been carried out with the Gaussian 16 software package. Absorption spectra were modeled as vertical transitions from the $S_{0}$ equilibrium geometry. Subsequently, to include dynamic and vibrational effects, 30 conformations, sampling the vicinity of the FrackCondon region, were generated through a Wigner distribution $^{89}$ as implemented in the Newton- $X^{90}$ software package. Vertical transitions from each snapshot were convoluted using Gaussian functions of full-width at half length (FWHL) of $0.15 \mathrm{eV}$. Absorption spectra calculations via
Wigner distribution method have been performed with B3LYP, PBEO, M062X, BLYP 83 and TPSSh ${ }^{83}$ functionals using the $6-31+G(d, p)$ basis set.

The nature of the excited states is evaluated using Natural Transition Orbitals (NTOs), obtained with the Nancy_EX $\operatorname{code}^{91,92}$ and visualized with the Chemissian ${ }^{93}$ and Avogadro ${ }^{94}$ software packages. In addition, $\Phi_{s}$ values, defining the overlap between the attachment and the detachment densities, were calculated. Spin-orbit couplings (SOC) between $\mathrm{S}_{1}$ and $T_{1}$ states have been calculated at the TDA level by using the Amsterdam Density Functional (ADF) $\operatorname{code}^{95,96}$ at the B3LYP/DZP ${ }^{97}$ and M06-2X/DZP levels of theory. DZP was used since Pople basis sets are not available in ADF. 


\section{Results and Discussion}

Herein, a series of different TADF emitters with various donor and acceptor groups were selected from the literature and were investigated by TDA-DFT methods (Figure 3). In an attempt to identify the presence of TADF characteristics in the selected emitters, several descriptors were assessed, such as the twisting angle between donor and acceptor units, $\Delta E_{\mathrm{ST}}$, NTO densities along with the charge transfer topology indices $\left(\Phi_{S}\right),{ }^{98}$ and SOC values between the $S_{1}$ and $T_{1}$ states involved in the RISC process.

We selected TADF compounds containing different acceptor groups, such as phosphine oxides, phenazines, anthraquinones, phenanthrenes, diphenylsulfones and benzophenones. Specifically, we consider the phosphine oxide (PX-ZPO, DPX-ZPO and TPX-ZPO ${ }^{99}$ ), dibenzo[a,j] phenazine (MeODP-DBPHZ, POZ-DBPHZ) ${ }^{100}$, anthraquinonebased compounds (AQ-DMAC, AQ-DPA), ${ }^{101}$ phenanthrene containing compounds (m-ATP-PXZ ${ }^{102}$, TPA-DCPP ${ }^{103}$ ) diphenylsulfone-based compounds (DMAC-DPS, PPZ-DPS) ${ }^{104}$ and benzophenone containing compounds ( $\mathrm{m}-\mathrm{PX} 2 \mathrm{BBP}$ and CZ2BP) ${ }^{105}$ Additionally, we studied PXZ-PXB bearing a $10 \mathrm{H}-$ phenoxaboryl electron acceptor group, ${ }^{106}$ DMAC-TRZ with 2,4,6-triphenyl-1,3,5-triazine (TRZ) acceptor moiety, ${ }^{107}$ and $2 \mathrm{CzPN}$ with dicyanobenzene group. ${ }^{108}$ Furthermore, and as a comparison, we also considered two non-TADF molecules namely, $\mathrm{pCBP}$ and $\mathrm{PhCz} .{ }^{109}$

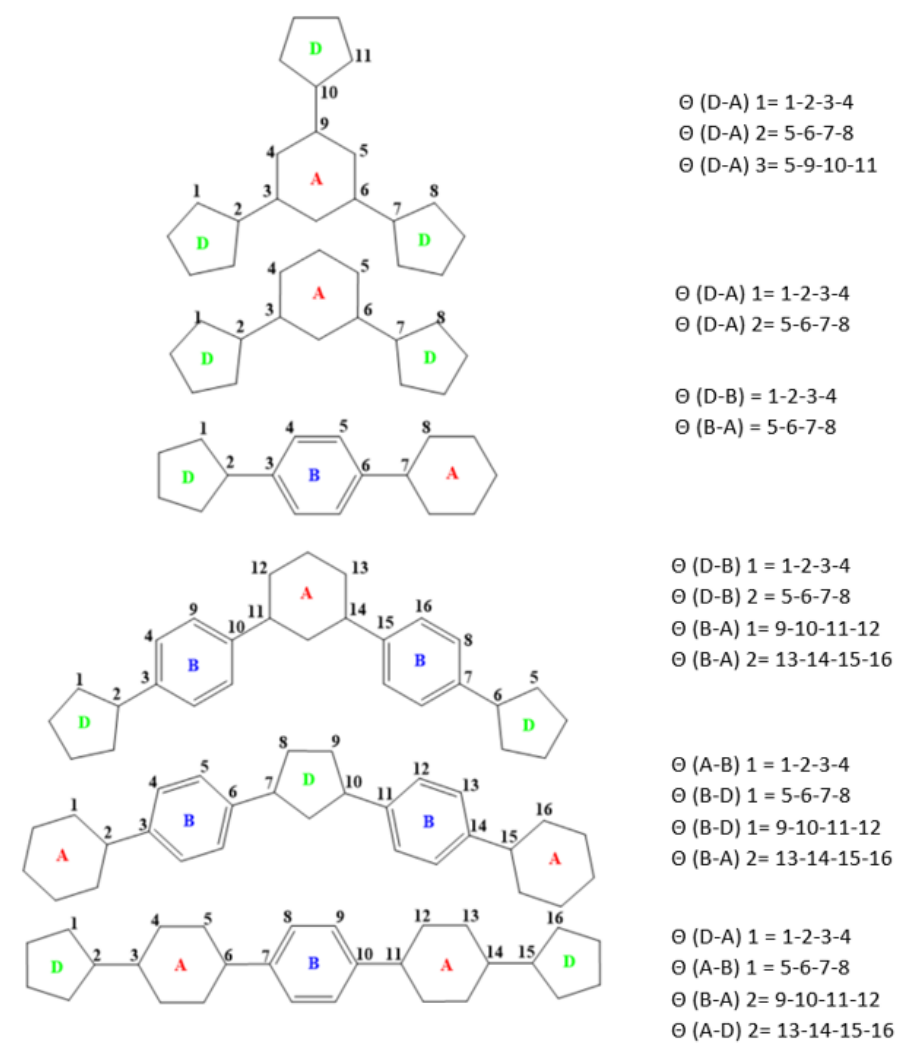

Twist Angle Between Donor (D), Acceptor (A) and Bridge (B)

\section{Moieties}

The torsion angle between donor/acceptor units and the bridge moieties is a straightforward descriptor allowing to rationalize the TADF activity, calculated values are reported in Figure 4. In fact, twisting angles of $90^{\circ}$ will constitute the perfect arrangement to break conjugation, thus leading to small $\Delta E_{S T}$ values and, hence, enhance TADF.

Among seven different donor units we show that the best performing group is clearly DMAC with its $\sim 90^{\circ}$ twisting, while PXZ moiety with $\sim 80^{\circ}$ twist angle is the second highest performing donor group.

As expected this favorable twist angle is reflected in PXZcontaining compounds with small $\Delta E_{\mathrm{ST}}$ values, as seen both experimentally and theoretically (Figure S2). PPZ and DHPZ displays a twisting of $\sim 100^{\circ}$ between the adjacent neighboring groups. These structural features also correlate with ideal $\Delta E_{\mathrm{ST}}$ values $(<0.1 \mathrm{eV})$ and well separated frontier orbitals as can be seen from Figure S3. On the contrary, TPA-DCPP, AQ-DPA and MeODP display relatively lower TADF activity due to their small twist angle, which are close to $30^{\circ}$. The small twisting can be attributed to the freely rotating phenyl rings, which cause a general planarization of the compounds. The last donor unit, $\mathrm{Cz}$, induces a torsion angle of around $50^{\circ}-60^{\circ}$.

Figure 4. Ground State Twist angles of TADF and Non-TADF molecules. 
Table 1. 3D representations of $S_{0}$ and $T_{1}$ geometries of some compounds with different ground state and excited state geometries and changes in torsion angles (M06-2X/6-31+G(d,p) level of theory).

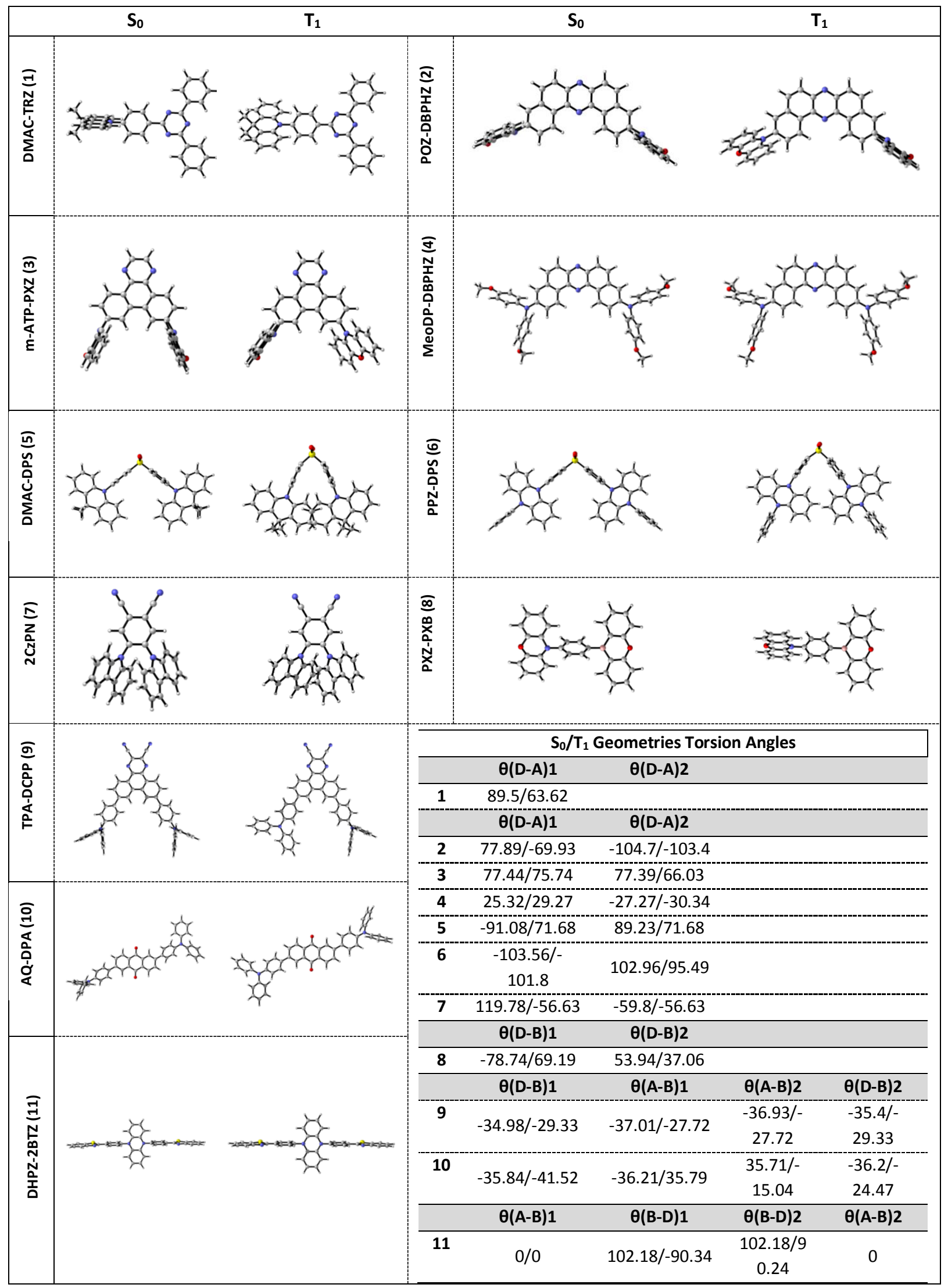


The relatively low torsion angle of the carbazole moiety can be attributed to a smaller steric repulsion due to the fivemembered ring in the donor group. In addition to the torsion angles between donor and adjacent moieties, we also examined the twisting angles between acceptor units and their adjacent donor or bridge moieties (Figure 4). While the triphenyl triazine acceptor induces a twisting angle of $90^{\circ}$, DBPHZ and m-ATP units reach approximately $80^{\circ}$.

On the other hand, the DPS moiety leads to an ideal $90^{\circ}$ twisting with DMAC and $100^{\circ}$ angle with PPZ group. Instead, relatively low performance TADF emitters, such as CZ2BP and $2 \mathrm{CzPN}$, assume a butterfly shape. Benzophenone-containing TADF emitters presenting a D-A-D scaffold, reach twist angles of $\sim 52^{\circ}$ and $\sim 120^{\circ}$ thus leading to a non-orthogonal geometry. However, due to its efficient ISC behavior, benzophenone was previously explored as an OLED emitter. ${ }^{59}$

In addition to the Franck-Condon region, the torsion angles at the equilibrium $T_{1}$ geometries were also examined, and, as reported in Table 1 , only slight changes can be observed. Overall, the geometry relaxation leads to a decrease in orthogonality, hence increasing the HOMO-LUMO overlap and $\Delta E_{\mathrm{ST}}$. As a matter of fact, excited state twisting is recognized as a key feature of TADF molecules.

To sum up, DMAC, PXZ and DHPZ units appear as the most appropriate donors to establish the desired orthogonality leading to twisting angles around $80^{\circ}$ and $100^{\circ}$. On the other hand, DPA derivatives have smaller twisting angles $\left(\sim 40^{\circ}\right)$, which lead to increased HOMO-LUMO overlap and $\Delta E_{\mathrm{ST}}$. Moreover, when considering acceptor moieties, anthraquinone and diphenylsulfone groups provide almost ideal orthogonal arrangements.

\section{Nature of States and Effect of the Functional}

The reorganization of the electronic density due to the excited state populations has been analyzed through the behavior of the corresponding NTOs. Furthermore, we compare the natures of $S_{1}$ and $T_{1}$ states obtained using M062X, CAM-B3LYP and $W B 97 X D$ to assess the influence of the exchange-correlation functional in the topology of the electron density reorganization (Table S10), and hence, in providing the correct diabatic description of the most relevant states. In this respect, B3LYP functional was excluded, since TADF compounds rely heavily on $\mathrm{CT}$, the known deficiencies of hybrid functionals become problematic, especially for bridged compounds leading to spatially long-range CT states. ${ }^{83}$

Table 2 reports the $\Phi_{s}$ values computed with M06-2X, $\omega B 97 X D$ and CAM-B3LYP functionals, while the corresponding NTO densities are reported in Table S10. As mentioned before, high $\Phi_{S}$ values indicate large overlap between electron and hole densities, thus, LE character. On the other hand, small $\Phi_{S}$ values indicate that the degree of overlap between electron and hole densities are small, and thus the presence of a CT excited state.

$\mathrm{S}_{1}$ states computed with M06-2X functional mostly present a noticeable CT character, which is known to favor TADF efficiency. Conversely, CAM-B3LYP and $\omega B$ 97XD functionals preview a locally excited $S_{1}$ state for some TADF compounds. Also taking into account the orthogonal arrangement, which should indeed favor charge separation, it appears that LE character should be regarded as an artifact as opposed to the more reliable M06-2X results (Table 3, see SI Table S11 for complete list). Hence, M06-2X will be consistently used hereafter.

Table 2. Phi-S values of $S_{1}$ states computed at different levels of theory and the $6-31+G(d, p)$ basis set.

\begin{tabular}{|c|c|c|c|}
\hline Phi-S Values & M062X & wB97XD & CAMB3LYP \\
\hline AQ-DMAC & 0.310 & 0.511 & 0.479 \\
\hline POZ-DBPHZ & 0.094 & 0.841 & 0.099 \\
\hline M-ATP-PXZ & 0.144 & 0.176 & 0.134 \\
\hline PXZ-PXB & 0.064 & 0.487 & 0.511 \\
\hline DMAC-TRZ & 0.213 & 0.503 & 0.519 \\
\hline m-PX2BBP & 0.247 & 0.525 & 0.549 \\
\hline DHPZ-2BTZ & 0.085 & 0.733 & 0.746 \\
\hline PPZ-DPS & 0.160 & 0.612 & 0.591 \\
\hline DMAC-DPS & 0.201 & 0.550 & 0.564 \\
\hline TPX-ZPO & 0.252 & 0.601 & 0.254 \\
\hline DPX-ZPO & 0.252 & 0.647 & 0.260 \\
\hline PX-ZPO & 0.212 & 0.525 & 0.235 \\
\hline TPA-DCPP & 0.728 & 0.588 & 0.612 \\
\hline AQ-DPA & 0.610 & 0.517 & 0.642 \\
\hline Cz2BP & 0.410 & 0.579 & 0.633 \\
\hline 2CzPN & 0.599 & 0.567 & 0.584 \\
\hline MeODP-DBPHZ & 0.739 & 0.483 & 0.514 \\
\hline PCBP & 0.782 & 0.497 & 0.587 \\
\hline $\mathrm{PhCz}$ & 0.847 & 0.862 & 0.863 \\
\hline
\end{tabular}

Table 3. Torsion angles and natures of $S_{1}$ states with different functionals.

\begin{tabular}{ccccc}
\hline \multirow{2}{*}{ Compounds } & $\begin{array}{c}\text { Torsion } \\
\text { Angle }\end{array}$ & M062X & CAM-B3LYP & wB97XD \\
\cline { 2 - 5 } & & $\mathbf{S}_{\mathbf{1}}$ & $\mathbf{S}_{\mathbf{1}}$ & $\mathbf{S}_{\mathbf{1}}$ \\
\hline AQ-DMAC & 89.39 & $\mathrm{CT}$ & $\mathrm{LE}$ & $\mathrm{CT}+\mathrm{LE}$ \\
\hline PXZ-PXB & 78.74 & $\mathrm{CT}$ & $\mathrm{LE}$ & $\mathrm{LE}$ \\
\hline DMAC-TRZ & 89.50 & $\mathrm{CT}$ & $\mathrm{CT}$ & $\mathrm{CT}$ \\
\hline PPZ-DPS & 103.56 & $\mathrm{CT}$ & $\mathrm{CT}+\mathrm{LE}$ & $\mathrm{CT}+\mathrm{LE}$ \\
\hline DMAC-DPS & 91.08 & $\mathrm{CT}$ & $\mathrm{CT}+\mathrm{LE}$ & $\mathrm{CT}+\mathrm{LE}$ \\
\hline TPX-ZPO & 103.6 & $\mathrm{CT}$ & $\mathrm{CT}+\mathrm{LE}$ & $\mathrm{CT}+\mathrm{LE}$ \\
\hline DPX-ZPO & 103.62 & $\mathrm{CT}$ & $\mathrm{CT}$ & $\mathrm{CT}+\mathrm{LE}$ \\
\hline
\end{tabular}




\section{Correlation between $\Delta \mathrm{E}_{\mathrm{S1}-\mathrm{T1}}$ and RISC Efficiency}

According to Kasha's Rule, ${ }^{73}$ the population of high lying singlet states is followed by ultrafast internal conversion (IC) to $S_{1}$, and eventually ISC leading to the population of the triplet manifold. IC is also active on the triplet manifold, hence leading to the $\mathrm{T}_{1}$ population. As a consequence, RISC will be mainly determined by the coupling between $T_{1}$ and $S_{1}$ as well as other higher singlet states. Bredas et al. have shown that the separation of frontier molecular orbitals alone is not sufficient to assure TADF efficiency and pointed to the fact that other factors, including the possibility of mixed CT $\mathrm{T}_{1}$ states with small $\Delta E_{\mathrm{ST}}$ gap, are crucial. ${ }^{110}$ The electron donating character of the donor moiety may also have a noticeable effect on $\Delta E_{\mathrm{ST}}$, with the increase of electron donation leading to its decrease. Additionally, using donor and acceptor moieties with appropriate ionization potentials and electron affinities is another key parameter in minimizing the $\Delta E_{\text {ST }}$ gap. ${ }^{72}$

As shown in Figure $5 \mathrm{~A}$ and Figure $\mathrm{S2}, \Delta E_{\mathrm{ST}}$ have been calculated with seven different functionals. PBEO yielded the smallest absolute deviations compared to experimental data reported in literature. However, it should be noted that, similar to the B3LYP functional, PBEO underestimates the excitation energies of CT states, hence can lead to an unphysical description of the low energy states.

On the other hand, the results obtained with M06-2X, which reproduces the nature of the excited states well, have larger absolute deviations from the experimental $\Delta E_{\mathrm{ST}}$ values, as shown in Table 4. However, it has to be taken into account that the range of experimentally available $\Delta E_{\mathrm{ST}}$ values is rather small, and certainly not sufficient to provide a statistically reliable correlation. Therefore, rather than focusing on the absolute values of $\Delta E_{\mathrm{ST}}$ data, we underline the correlation with

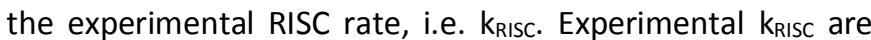
available only for five compounds of our set, namely TPX-ZPO,
DPX-ZPO, PX-ZPO, AQ-DPA, and 2CZPN. Of note, $\mathrm{k}_{\mathrm{RISC}}$ has been computed using Equation 3, which shows the inverse relation between the energy gap and the RISC probability.

Table 4. Experimental and theoretical $\triangle E_{S T}$ values of compounds TPX-ZPO, DPX-ZPO, PX-ZPO, AQ-DPA and 2CZPN.

\begin{tabular}{ccc}
\hline & Exp & M062X \\
\hline Compounds (C) & $\Delta \mathrm{E}_{\mathrm{S1} \text {-T1 }}$ & $\Delta \mathrm{E}_{\mathrm{S1} \text {-T1 }}$ \\
\hline TPX-ZPO (1) & 0.110 & 0.319 \\
\hline DPX-ZPO (2) & 0.190 & 0.332 \\
\hline PX-ZPO (3) & 0.260 & 0.362 \\
\hline AQ-DPA (4) & 0.250 & 0.402 \\
\hline 2CZPN (5) & 0.310 & 0.457 \\
\hline
\end{tabular}

To stress the relation between $\Delta E_{\mathrm{ST}}$ and the electronic density reorganization, we report in Figure $5, \Delta E_{S T}$ (panel $5 A$ ) and $\Phi_{S}$ (panel $5 B$ ) values calculated with different functionals and the $6-31+G(d, p)$ basis set. Once again, the results are coherent in pinpointing the direct relation between the amount of $\mathrm{CT}$ and the narrowing of the singlet/triplet gap. Hence, the beneficial role of CT states in favoring RISC and thus, TADF is once more confirmed.

Figure 6 represents the relation between the experimental RISC rate constants and $\Delta E_{S T}$ obtained with CAM-B3LYP, WB97XD and M06-2X functionals. A stunning behavior of CAM-B3LYP and WB97XD functionals is observed leading to a negative correlation between $\mathrm{k}_{\mathrm{RISC}}$ values and $1 / \Delta E_{S T}$ values. However, this can also be correlated to the bad description of $\mathrm{S}_{1}$ provided by these functionals and pointed out in the previous section. On the other hand, M06-2X yields the expected linear trend. Indeed, M06-2X provides a more pronounced CT character for the lowest lying excited states, which is in better agreement with the experimental evidence as shown in Table S10.

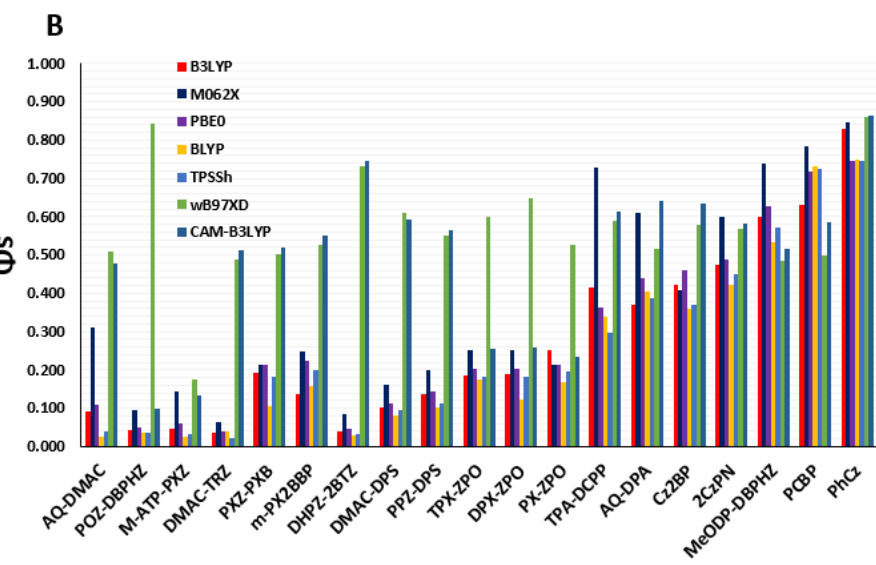

Figure 5. $\Delta E_{S T}$ and $\Phi_{S}$ parameter computed with seven different functionals and 6-31+G(d,p) basis set. 

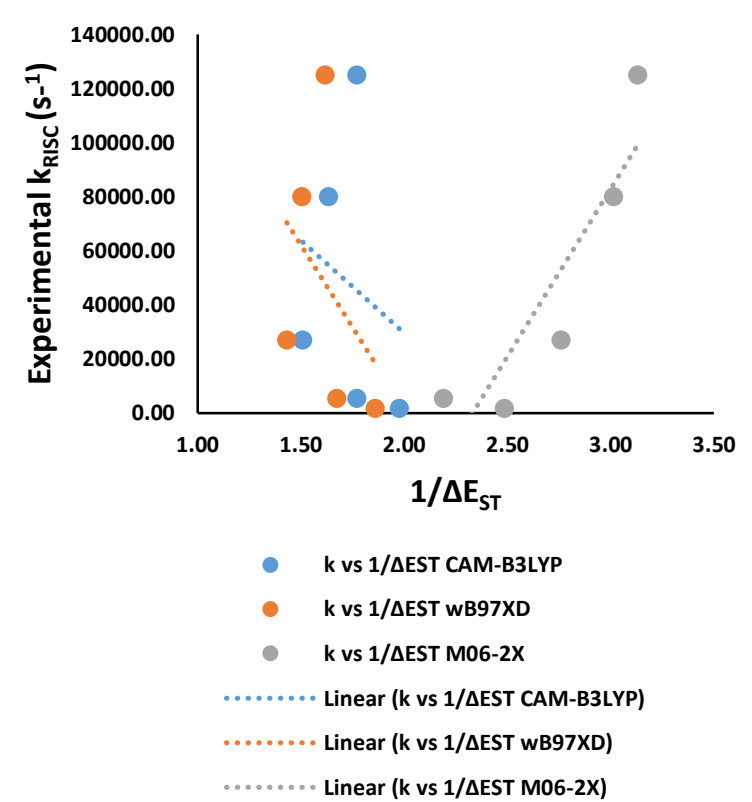

Figure 6. Relation between $k_{\text {RISC }}$ values and $1 / \Delta E_{S T}$ values computed with CAM-B3LYP, WB97XD and M06-2X functionals and $6-31+G(d, p)$ basis set.

\section{Correlation between SOC and RISC Efficiency}

Besides the $\Delta E_{S T}$ descriptor, we also determined the effects of structural modifications on the SOC between $S_{1}$ and $T_{1}$ states. Indeed, despite giving rise to low lying CT with negligible electron-hole overlap, orthogonal arrangement of donor and acceptor moieties may have a negative effect on SOC, hence influencing in a more subtle way the ultimate RISC rate.

Although TADF compounds are generally known to have low SOC values, it is found that RISC occur on a timescale shorter than $100 \mathrm{~ns}$ at $300 \mathrm{~K} .{ }^{110}$ Furthermore, LE triplet states may be involved increasing the possibility of RISC following El Sayed's rule. ${ }^{111,112}$ In this context, Penfold and Monkman suggested a
RISC mechanism which involves a three state degeneracy between $\mathrm{S}_{\mathrm{CT}}, \mathrm{T}_{\mathrm{CT}}$ and $\mathrm{T}_{\mathrm{LE}} .{ }^{113}$

Herein, we computed $\mathrm{SOC}$ values for both equilibrium $\mathrm{S}_{0}$ and $\mathrm{T}_{1}$ geometries (Table S12). It should be noted that SOC at the two equilibrium geometries are strikingly different, and since we are dealing with RISC from $T_{1}$ to $S_{1}$, SOCs obtained on top of the equilibrium $T_{1}$ geometry are more physically appropriate. Figure 7 represents SOC computed with the M062X functional, and, as expected, these values are coherently reflecting the coupling between $\mathrm{CT}$ singlet and LE triplet states.

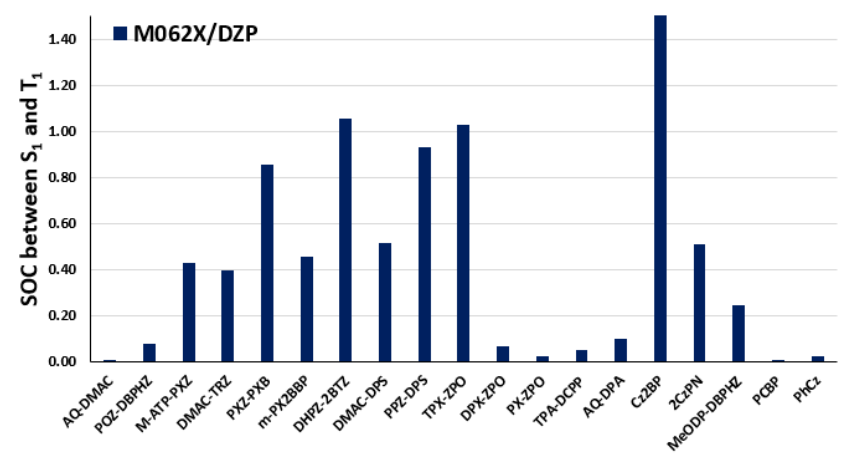

Figure 7. Graph representing $S O C$ values computed with M062X functional and DZP basis set on $T_{1}$ geometries.

To understand the correlation of the calculated values with experiment, the $S O C$ and $\Delta E_{S T}$ descriptors were used to obtain, as shown in Equation 3, the first order mixing coefficients $\chi$, which are reported in Figure 8. More specifically, Figure $8 \mathrm{~A}$ represents the relation of $\chi$ with the experimental RISC rate constant and Figure $8 \mathrm{~B}$ represents the correlation of $\mathrm{SOC}$ and $\Delta E_{S T}$ with $\chi$. It has been observed (Figure $8 \mathrm{~A}$ ) that experimental RISC rate constants of the selected compounds are directly proportional to the $\chi$ values obtained from the computed SOC and $\Delta E_{\text {ST. }}$

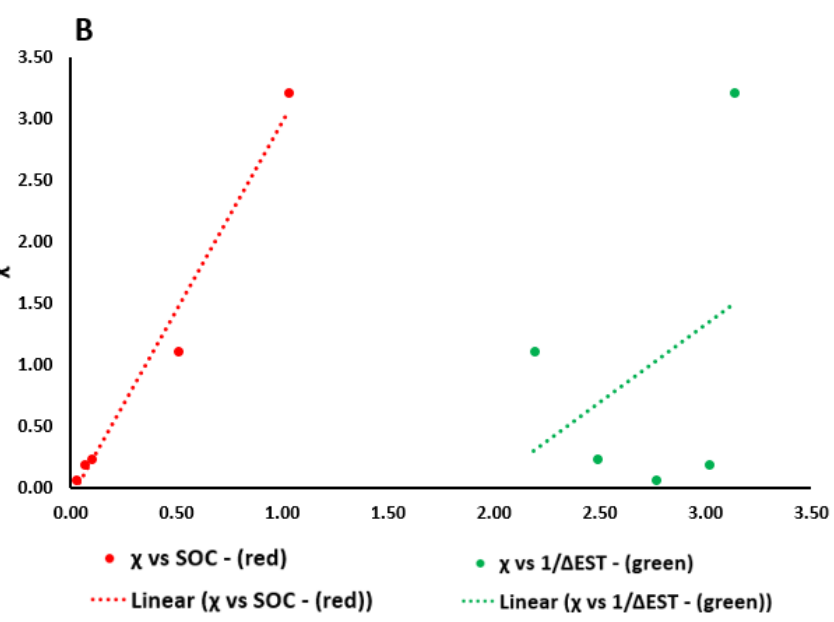

Figure 8. Graphs representing the correlation between experimental $k_{\text {RISC }}$ and descriptors studied with M062X functional. 
Conversely, in Figure 8B, we examine the relation between $\chi$ and two descriptors, namely SOC and $\Delta E_{\mathrm{ST}}$. We observe that the relation between $\chi$ and SOC yields a rather linear correlation as witnessed by the square of the correlation coefficient $R^{2}$ (0.98). On the other hand, the relation with $1 / \Delta E_{\mathrm{ST}}$ shows a much less regular behavior and a very small $\mathrm{R}^{2}$ of about 0.14 . Hence, it appears that SOC is a more promising, and more well-behaved descriptor than the more widely used $\Delta E_{\mathrm{ST}}$ in providing a consistent description of TADF efficiency. Additionally, while it has been observed that no consistent relation between SOC and $\Delta E_{\mathrm{ST}}$ can be inferred from our data, it also appears that threshold values of $\Delta E_{\mathrm{ST}}$ are necessary to assure RISC. Globally, improving $k_{\text {RISc }}$ may be achieved by the enhancement of SOC through appropriate molecular designs.

It should also be noted that in our test-set, various TADF groups are represented and in all the cases the SOC descriptor was able to reliably describe the experimental efficiency, even in the presence of wide and diverse donor and acceptor groups, and in general different functional groups.

To build on top of these results, $\chi$ calculations were performed for the whole set of molecules and the relationship between SOC and $\chi$ is shown in Figure 9. Albeit a slightly larger variability, mainly due to the presence of a few outliers, the linear relationship previously observed still holds. This confirms the role of SOC as the most robust and suitable parameter to infer TADF efficiency.

Globally, remarkable TADF efficiency requires either moderate SOC and very small $\Delta \mathrm{E}_{\mathrm{S} 1-\mathrm{T} 1}$ or moderate $\Delta \mathrm{E}_{\mathrm{S} 1-\mathrm{T} 1}$ and very high SOC. Thus, almost perfectly orthogonal scaffolds including strong $D$ and $A$ moieties, which will results in very small $\Delta \mathrm{E}_{\mathrm{S1}-\mathrm{T} 1}$ and SOC values, will be less efficient than moderate strength $D$ and $A$ groups if they still present torsion angles leading to acceptable $\Delta \mathrm{E}_{\mathrm{S1}-\mathrm{T} 1}$ and strong SOC.

A

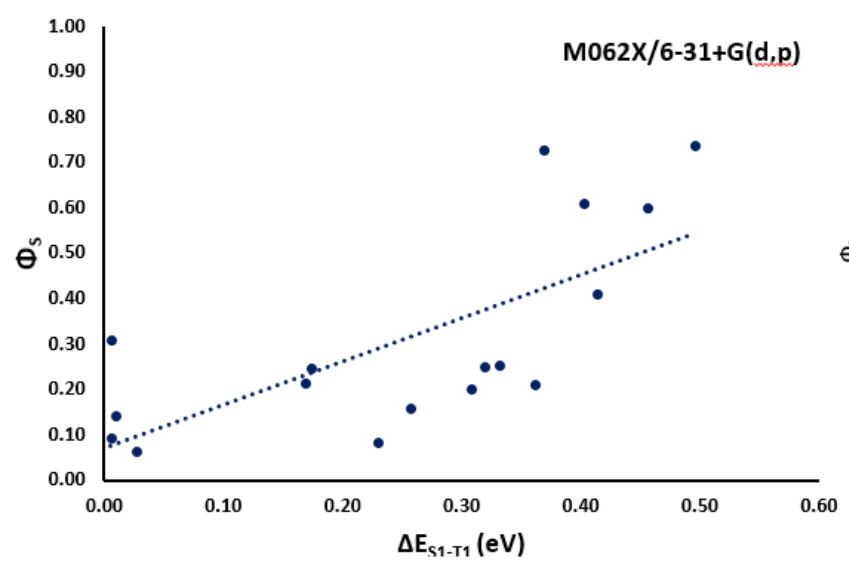

\section{Topological $\Phi_{\mathrm{s}}$ Index}

The $\Phi_{S}$ index measures the degree of overlap between particle and hole densities, and the smaller its value the larger the charge separation in the excited states.

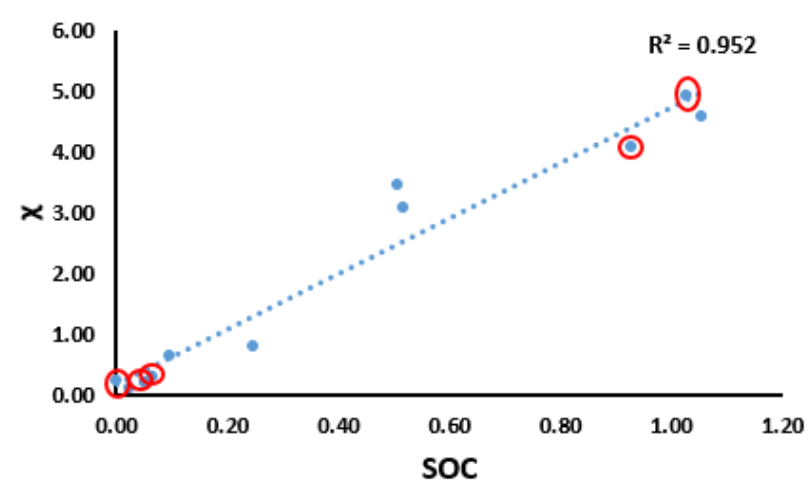

Figure 9. Graph representing the direct relation between $\mathrm{SOC}$ and $\chi$. (SOC with M062X/DZP and $\Delta E_{\mathrm{ST}}$ with M062X/6$31+G(d, p)$. Red circles indicate the molecules with experimental $k_{\mathrm{RISC}}$ values.

Hence, the $\Phi_{s}$ index can be used as an indicator for TADF efficiencies. As represented in Figure $10 \mathrm{~A}, \Phi_{\mathrm{s}}$ indices increase with the increase in $\Delta E_{\mathrm{S} 1-\mathrm{T} 1}$ values.

This situation is also coherent with the decrease of orthogonality and triplet twisting behavior discussed previously. It also represents a favorable strategy to increase RISC, since it correlates to a partial mixing between CT and LE states. Compounds with the smallest twisting angles between donor and acceptor units, such as CZ2BP, MeODP-DBPHZ, TPA-DCPP and AQ-DPA, or the non-TADF compounds pCBP and $\mathrm{PhCz}$ with high $\triangle E_{\mathrm{ST}}$ values have higher $\Phi_{\mathrm{S}}$ indices, because of the highly delocalized $\pi$ electrons, which result in hole and particle density overlap and increased LE character (Figure S3).

Figure 10. $\Phi_{\mathrm{s}}$ values computed at M06-2X/6-31+G(d,p) level of theory and its relation with SOC parameters. 
On the other hand, compounds with higher twisting angles and lower $\Delta E_{S T}$ values exhibit lower $\Phi_{S}$ indices, which indicates increased CT character. ${ }^{114}$

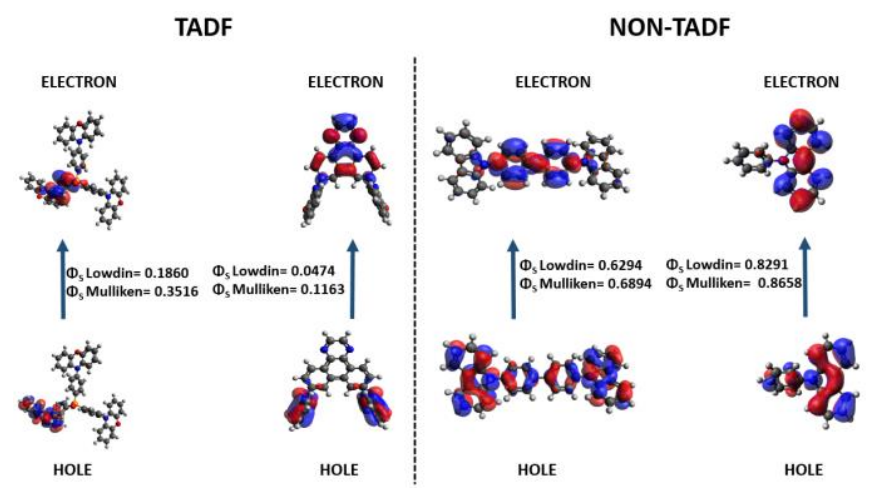

Figure 11. $\Phi_{S}$ indices and frontier molecular orbital overlap differences of TADF TPX-ZPO, m-ATPPXZ and non-TADF pCBP, $\mathrm{PhCz}$ molecules, respectively.

As shown in Figures 10 and 11, while most of the TADF compounds have $\Phi_{s}$ values smaller than 0.3, non-TADF compounds have $\Phi_{s}$ values close to unity. This is due to TADF active molecules MeODP, Cz2BP, TPA-DCPP, AQ-DPA and Non-TADF pCBP, PhCz, which have torsion angles far from $90^{\circ}$, present hole and particle densities delocalized over the conjugated bridges (Figure S3), thus causing an increase in $\Phi_{\mathrm{S}}$ values (Table 3).

However, for compounds which have orthogonal D-A geometries, such as DMAC-TRZ, DMAC-DPS and AQ-DMAC, hole densities are distributed on the donor moieties while particle densities are almost perfectly localized on the acceptor groups.

\section{Conclusion}

Through a systematic study of a large panel of potential TADF chromophores we have elucidated the reasons behind the performance of the different descriptors, which may be used to forecast RISC probability. Singlet/triplet gap, $\Delta E_{\mathrm{ST}}$, is highly associated with twisting angle and the presence of strong electron donating and withdrawing groups. The results obtained with M06-2X are reliable and consistent with experimental behaviors. Additionally, we also observed a significant deviation of the twisting angles of TADF molecules between ground and excited state equilibrium geometries.

The determination of the SOC, calculated from the optimized $\mathrm{T}_{1}$ geometries, and the related RISC probability, points out that SOC actually appears to be the most reliable descriptor of TADF activity.

As the electronic density reorganization seems fundamental to assure TADF, $\Phi_{\mathrm{S}}$ index has been explicitly considered. A good correlation has been observed with the structural properties, such as the twisting angles or the $\Delta E_{\mathrm{ST}}$ values, also coherently with previous reported trends. ${ }^{114}$

To sum up, our calculations successfully explain the descriptor trends within various types of molecular architectures. Additionally, we explored a wide range of donor and acceptor groups and their characteristic structural behaviors, which determine their performances in TADF applications. While singlet-triplet gaps may provide threshold values, to globally distinguish between TADF and non-TADF compounds, SOC may lead to a more quantitative correlation with RISC propensity. Hence, both descriptors should be combined when performing computational screening and rational molecular design.

\section{Conflicts of interest}

There are no conflicts of interest to declare.

\section{Acknowledgements}

This work is partially supported by the LPCT resources and TUBITAK ULAKBIM High Performance and Grid Computing Center (TRUBA resources). SC and PU thank TUBITAK (Project Number: 118Z914) and BAP-M (16863) for financial support.

\section{Notes and references}

${ }^{1}$ C.W. Tang and S.A. Vanslyke, Appl. Phys. Lett. 51, 913 (1987).

${ }^{2}$ Q. Zhang, H. Kuwabara, W.J. Potscavage, S. Huang, Y. Hatae, T. Shibata, and C. Adachi, J. Am. Chem. Soc. 136, 18070 (2014).

${ }^{3}$ H. Uoyama, K. Goushi, K. Shizu, H. Nomura, and C. Adachi, Nature 492, 234 (2012).

${ }^{4}$ R.H. Chien, C.T. Lai, and J.L. Hong, J. Phys. Chem. C 115, 5958 (2011).

${ }^{5}$ D. Jacquemin and D. Escudero, Chem. Sci. 8, 7844 (2017).

${ }^{6}$ D.G. Congrave, B.H. Drummond, P.J. Conaghan, H. Francis, S.T.E. Jones, C.P. Grey, N.C. Greenham, D. Credgington, and H. Bronstein, J. Am. Chem. Soc. 141, 18390 (2019).

7 S. Izumi, H.F. Higginbotham, A. Nyga, P. Stachelek, N. Tohnai, P. de Silva, P. Data, Y. Takeda, and S. Minakata, J. Am. Chem. Soc. 142, 1482 (2020).

${ }^{8}$ M.-Y. Leung, M.-C. Tang, W.-L. Cheung, S.-L. Lai, M. Ng, M.Y. Chan, and V. Wing-Wah Yam, J. Am. Chem. Soc. jacs. 9b12136 (2020).

${ }^{9}$ V. Jankus, P. Data, D. Graves, C. McGuinness, J. Santos, M.R. Bryce, F.B. Dias, and A.P. Monkman, Adv. Funct. Mater. 24, 6178 (2014).

${ }^{10}$ T. Serevičius, T. Nakagawa, M.C. Kuo, S.H. Cheng, K.T. Wong, C.H. Chang, R.C. Kwong, S. Xia, and C. Adachi, Phys. Chem. Chem. Phys. 15, 15850 (2013).

${ }^{11}$ L. Zhan, Z. Chen, S. Gong, Y. Xiang, F. Ni, X. Zeng, G. Xie, and C. Yang, Angew. Chemie - Int. Ed. 58, 17651 (2019). 
${ }^{12}$ K. Zheng, F. Ni, Z. Chen, C. Zhong, and C. Yang, Angew. Chemie - Int. Ed. 1 (2019).

${ }^{13}$ B.S. Kim and J.Y. Lee, Adv. Funct. Mater. 24, 3970 (2014).

${ }^{14}$ Q. Zhang, S. Xu, M. Li, Y. Wang, N. Zhang, Y. Guan, M. Chen, C.F. Chen, and H.Y. Hu, Chem. Commun. 55, 5639 (2019).

${ }^{15}$ X. Li, G. Baryshnikov, C. Deng, X. Bao, B. Wu, Y. Zhou, H. Ågren, and L. Zhu, Nat. Commun. 10, 1 (2019).

${ }^{16}$ C.M. Tonge and Z.M. Hudson, J. Am. Chem. Soc. 141, 13970 (2019).

17 Y.J. Yu, X. Tang, H.T. Ge, Y. Yuan, Z.Q. Jiang, and L.S. Liao, Org. Electron. Physics, Mater. Appl. 73, 240 (2019).

${ }^{18} \mathrm{C}$. Wu, Y. Zhang, D. Ma, and Q. Wang, Dye. Pigment. 173, 107895 (2020).

${ }^{19}$ D. Chen, X. Cai, X.L. Li, Z. He, C. Cai, D. Chen, and S.J. Su, J. Mater. Chem. C 5, 5223 (2017).

${ }^{20}$ Y.J. Yu, X. Tang, H.T. Ge, Y. Yuan, Z.Q. Jiang, and L.S. Liao, Org. Electron. Physics, Mater. Appl. 73, 240 (2019).

${ }^{21}$ J.H. Kim, J.H. Yun, and J.Y. Lee, Adv. Opt. Mater. 6, (2018).

${ }^{22}$ M. Cekaviciute, J. Simokaitiene, D. Volyniuk, G. Sini, and J. V. Grazulevicius, Dye. Pigment. 140, 187 (2017).

${ }^{23}$ Q. Zhang, J. Li, K. Shizu, S. Huang, S. Hirata, H. Miyazaki, and C. Adachi, J. Am. Chem. Soc. 134, 14706 (2012).

${ }^{24}$ P. Rajamalli, D. Rota Martir, and E. Zysman-Colman, J. Photonics Energy 8, 1 (2018).

${ }^{25}$ C. Fan, C. Duan, Y. Wei, D. Ding, H. Xu, and W. Huang, Chem. Mater. 27, 5131 (2015).

${ }^{26}$ S. Hirata, Y. Sakai, K. Masui, H. Tanaka, S.Y. Lee, H. Nomura, N. Nakamura, M. Yasumatsu, H. Nakanotani, Q. Zhang, K. Shizu, H. Miyazaki, and C. Adachi, Nat. Mater. 14, 330 (2015).

${ }^{27}$ T. Northey and T.J. Penfold, Org. Electron. 59, 45 (2018).

${ }^{28}$ T.T. Bui, F. Goubard, M. Ibrahim-Ouali, D. Gigmes, and F. Dumur, Beilstein J. Org. Chem. 14, 282 (2018).

${ }^{29}$ J.R. Cha, C.W. Lee, and M.S. Gong, Dye. Pigment. 140, 399 (2017).

${ }^{30}$ H. Nakanotani, T. Higuchi, T. Furukawa, K. Masui, K.

Morimoto, M. Numata, H. Tanaka, Y. Sagara, T. Yasuda, and C. Adachi, Nat. Commun. 5, 1 (2014).

${ }^{31}$ S.Y. Lee, T. Yasuda, Y.S. Yang, Q. Zhang, and C. Adachi, Angew. Chemie 126, 6520 (2014).

${ }^{32}$ Y. Qi, Z. Wang, S. Hou, and J. Yu, Org. Electron. Physics, Mater. Appl. 43, 112 (2017).

${ }^{33}$ K. Matsuo and T. Yasuda, Chem. Sci. 10, 10687 (2019).

${ }^{34}$ S. Sohn, B. Hyun Koh, J.Y. Baek, H. Chan Byun, J.H. Lee, D.S. Shin, H. Ahn, H.K. Lee, J. Hwang, S. Jung, and Y.H. Kim, Dye. Pigment. 140, 14 (2017).

${ }^{35}$ Y. Gao, Q.Q. Pan, L. Zhao, Y. Geng, T. Su, T. Gao, and Z.M. Su, Chem. Phys. Lett. 701, 98 (2018).

${ }^{36}$ K. Wang, W. Liu, C.J. Zheng, Y.Z. Shi, K. Liang, M. Zhang, X.M. Ou, and X.H. Zhang, J. Mater. Chem. C 5, 4797 (2017).

37 S. Feng, X. Guo, and J. Zhang, Spectrochim. Acta - Part A Mol. Biomol. Spectrosc. 226, (2020).

${ }^{38}$ M.P. Gaj, C. Fuentes-Hernandez, Y. Zhang, S.R. Marder, and B. Kippelen, Org. Electron. Physics, Mater. Appl. 16, 109 (2015).

${ }^{39}$ T. Hosokai, H. Nakanotani, S. Santou, H. Noda, Y.
Nakayama, and C. Adachi, Synth. Met. 252, 62 (2019).

40 T. Serevičius, T. Nakagawa, M.C. Kuo, S.H. Cheng, K.T. Wong, C.H. Chang, R.C. Kwong, S. Xia, and C. Adachi, Phys. Chem. Chem. Phys. 15, 15850 (2013).

${ }^{41}$ B. Huang, Q. Qi, W. Jiang, J. Tang, Y. Liu, W. Fan, Z. Yin, F. Shi, X. Ban, H. Xu, and Y. Sun, Dye. Pigment. 111, 135 (2014).

${ }^{42}$ S.Y. Byeon, J.H. Kim, and J.Y. Lee, ACS Appl. Mater. Interfaces 9, 13339 (2017).

${ }^{43}$ P. Rajamalli, N. Senthilkumar, P. Gandeepan, P.Y. Huang, M.J. Huang, C.Z. Ren-Wu, C.Y. Yang, M.J. Chiu, L.K. Chu, H.W. Lin, and C.H. Cheng, J. Am. Chem. Soc. 138, 628 (2016).

${ }^{44}$ L. Wang, J. Jin, W. Zhang, B. Pan, Z. Huang, and S. Zhuang, Org. Electron. Physics, Mater. Appl. 16, 177 (2015).

${ }^{45}$ Y.J. Lien, T.C. Lin, C.C. Yang, Y.C. Chiang, C.H. Chang, S.H. Liu, Y.T. Chen, G.H. Lee, P.T. Chou, C.W. Lu, and Y. Chi, ACS Appl. Mater. Interfaces 9, 27090 (2017).

${ }^{46}$ H. Tanaka, K. Shizu, H. Miyazaki, and C. Adachi, Chem. Commun. 48, 11392 (2012).

${ }^{47}$ Y. Olivier, M. Moral, L. Muccioli, and J.C. Sancho-García, J. Mater. Chem. C 5, 5718 (2017).

${ }^{48}$ K. Wu, T. Zhang, L. Zhan, C. Zhong, S. Gong, N. Jiang, Z.H. Lu, and C. Yang, Chem. - A Eur. J. 22, 10860 (2016).

${ }^{49}$ Y. Kitamoto, T. Namikawa, D. Ikemizu, Y. Miyata, T. Suzuki, H. Kita, T. Sato, and S. Oi, J. Mater. Chem. C 3, 9122 (2015).

${ }^{50}$ G. Jiang, F. Li, X. Kong, J. Fan, Y. Song, C. Wang, and L. Lin, J. Lumin. 116899 (2019).

${ }^{51}$ C.C. Tsai, W.C. Huang, H.Y. Chih, Y.C. Hsh, C.W. Liao, C.H. Lin, Y.X. Kang, C.H. Chang, Y.J. Chang, and C.W. Lu, Org. Electron. 63, 166 (2018).

52 T. Northey and T.J. Penfold, Org. Electron. 59, 45 (2018).

${ }^{53}$ M. Mamada, G. Tian, H. Nakanotani, J. Su, and C. Adachi, Angew. Chemie 130, 12560 (2018).

${ }^{54}$ K. Suzuki, S. Kubo, K. Shizu, T. Fukushima, A. Wakamiya, Y. Murata, C. Adachi, and H. Kaji, Angew. Chemie - Int. Ed. 54, 15231 (2015).

${ }^{55}$ Y.J. Shiu, Y.T. Chen, W.K. Lee, C.C. Wu, T.C. Lin, S.H. Liu, P.T. Chou, C.W. Lu, I.C. Cheng, Y.J. Lien, and Y. Chi, J. Mater. Chem. C 5, 1452 (2017).

${ }^{56}$ X. Liang, Z.P. Yan, H.B. Han, Z.G. Wu, Y.X. Zheng, H. Meng, J.L. Zuo, and W. Huang, Angew. Chemie - Int. Ed. 57, 11316 (2018).

${ }^{57}$ Y.J. Shiu, Y.C. Cheng, W.L. Tsai, C.C. Wu, C.T. Chao, C.W. Lu, Y. Chi, Y.T. Chen, S.H. Liu, and P.T. Chou, Angew. Chemie Int. Ed. 55, 3017 (2016).

${ }^{58}$ Y. Gao, Q.Q. Pan, L. Zhao, Y. Geng, T. Su, T. Gao, and Z.M. Su, Chem. Phys. Lett. 701, 98 (2018).

${ }^{59}$ S.Y. Lee, T. Yasuda, Y.S. Yang, Q. Zhang, and C. Adachi, Angew. Chemie 126, 6520 (2014).

${ }^{60}$ A. Tomkeviciene, T. Matulaitis, M. Guzauskas, V. Andruleviciene, D. Volyniuk, and J.V. Grazulevicius, Org. Electron. 70, 227 (2019).

${ }^{61}$ S. Youn Lee, T. Yasuda, H. Nomura, and C. Adachi, Appl. Phys. Lett. 101, 9 (2012).

62 T. Hosokai, H. Matsuzaki, H. Nakanotani, K. Tokumaru, T. Tsutsui, A. Furube, K. Nasu, H. Nomura, M. Yahiro, and C. Adachi, Sci. Adv. 3, 1 (2017).

${ }^{63}$ Y.K. Wang, S.F. Wu, Y. Yuan, S.H. Li, M.K. Fung, L.S. Liao, 
and Z.Q. Jiang, Org. Lett. 19, 3155 (2017).

${ }^{64}$ T. Nakagawa, S.Y. Ku, K.T. Wong, and C. Adachi, Chem.

Commun. 48, 9580 (2012).

${ }^{65}$ M.Y. Wong and E. Zysman-Colman, Adv. Mater. 29, (2017).

${ }^{66}$ D.S.M. Ravinson and M.E. Thompson, Mater. Horizons (2020).

67 S. Kothavale, W.J. Chung, and J.Y. Lee, J. Mater. Chem. C 10, (2020).

${ }^{68}$ F.B. Dias, J. Santos, D.R. Graves, P. Data, R.S. Nobuyasu,

M.A. Fox, A.S. Batsanov, T. Palmeira, M.N. Berberan-Santos, M.R. Bryce, and A.P. Monkman, Adv. Sci. 3, 1 (2016).

${ }^{69}$ I. Lyskov and C.M. Marian, J. Phys. Chem. C 121, 21145 (2017).

${ }^{70}$ S. Xu, Q. Yang, Y. Wan, R. Chen, S. Wang, Y. Si, B. Yang, D. Liu, C. Zheng, and W. Huang, J. Mater. Chem. C 7, 9523 (2019).

${ }^{71}$ J.T. Ye, H.Q. Wang, Y. Zhang, and Y.Q. Qiu, J. Phys. Chem. C (2020).

72 J.M. Mewes, Phys. Chem. Chem. Phys. 20, 12454 (2018).

${ }^{73}$ Y.H. Shi, F. Wang, M.Y. Sui, G.Y. Sun, and Y.Z. Xie, Adv. Theory Simulations 2000037, 1 (2020).

${ }^{74}$ I. Frisch, M. J.; Trucks, G. W.; Schlegel, H. B.; Scuseria, G. E.; Robb, M. A.; Cheeseman, J. R.; Scalmani, G.; Barone, V.; Petersson, G. A.; Nakatsuji, H.; Li, X.; Caricato, M.; Marenich, A. V.; Bloino, J.; Janesko, B. G.; Gomperts, R.; Mennucci, B.; Hratch, (n.d.).

${ }^{75}$ B. Zhao, Z. Liu, Z. Wang, H. Zhang, J. Li, H. Wang, B. Xu, Y. $\mathrm{Wu}$, and W. Li, Org. Electron. 73, 1 (2019).

${ }^{76}$ Y. Zhao and D.G. Truhlar, Theor. Chem. Acc. 120, 215 (2008).

${ }^{77}$ A. Kolleth, S. Müller, A. Lumbroso, G. Tanriver, S. Catak, S. Sulzer-Mossé, and A. De Mesmaeker, Tetrahedron Lett. 59, 3242 (2018).

${ }^{78}$ A. Kolleth, A. Lumbroso, G. Tanriver, S. Catak, S. SulzerMossé, and A. De Mesmaeker, Tetrahedron Lett. 58, 2904 (2017).

79 D. Josa, J. Rodríguez-Otero, E.M. Cabaleiro-Lago, and M. Rellán-Piñeiro, Chem. Phys. Lett. 557, 170 (2013).

${ }^{80}$ E.E. Bas, P. Ulukan, A. Monari, V. Aviyente, and S. Catak, ChemRxiv Preprint, https://doi.org/10.33774/chemrxiv2021-9htkb, (2021).

${ }^{81}$ A.D. Becke, J. Chem. Phys. 98, 1372 (1993).

82 T. Yanai, D.P. Tew, and N.C. Handy, Chem. Phys. Lett. 393, 51 (2004).

${ }^{83}$ B. Albert and N. Cedex, 5 (n.d.).

${ }^{84}$ A. Kolleth, S. Müller, A. Lumbroso, G. Tanriver, S. Catak, S. Sulzer-Mossé, and A. De Mesmaeker, Tetrahedron Lett. 59, 3242 (2018).

${ }^{85}$ A. Zabaradsti, A. Kakanejadifard, and M. Ghasemian, Comput. Theor. Chem. 989, 1 (2012).

${ }^{86}$ J. Tomasi and M. Persico, Chem. Rev. 94, 2027 (1994).

${ }^{87}$ C.Y. Legault, (n.d.).

${ }^{88}$ M.J.G. Peach, M.J. Williamson, and D.J. Tozer, J. Chem. Theory Comput. 7, 3578 (2011).

${ }^{89}$ J.P. Dahl and M. Springborg, J. Chem. Phys. 88, 4535 (1988).

${ }^{90}$ M. Barbatti, M. Ruckenbauer, F. Plasser, J. Pittner, G.
Granucci, M. Persico, and H. Lischka, Wiley Interdiscip. Rev. Comput. Mol. Sci. 4, 26 (2014).

91 T. Etienne, X. Assfeld, and A. Monari, J. Chem. Theory Comput. 10, 3906 (2014).

92 T. Etienne, X. Assfeld, and A. Monari, J. Chem. Theory Comput. 10, 3896 (2014).

93 L. Skripnikov, (2020).

${ }^{94}$ M.D. Hanwell, D.E. Curtis, D.C. Lonie, T. Vandermeerschd, E. Zurek, and G.R. Hutchison, J. Cheminform. 4, (2012).

${ }^{95}$ G. te Velde, F.M. Bickelhaupt, E.J. Baerends, C. Fonseca Guerra, S.J.A. van Gisbergen, J.G. Snijders, and T. Ziegler, J. Comput. Chem. 22, 931 (2001).

${ }^{96}$ C. Fonseca Guerra, J.G. Snijders, G. Velde, and E.J. Baerends, Theor. Chem. Acc. 99, 391 (1998).

${ }^{97} \mathrm{E}$. Van Lenthe and E.J. Baerends, J. Comput. Chem. 24, 1142 (2003).

${ }^{98}$ M. Girardon, S. Parant, A. Monari, F. Dehez, C. Chipot, E. Rogalska, N. Canilho, and A. Pasc, ChemPhotoChem 3, 1034 (2019).

${ }^{99}$ C. Duan, J. Li, C. Han, D. Ding, H. Yang, Y. Wei, and H. Xu, Chem. Mater. 28, 5667 (2016).

100 P. Data, P. Pander, M. Okazaki, Y. Takeda, S. Minakata, and A.P. Monkman, Angew. Chemie - Int. Ed. 55, 5739 (2016).

${ }^{101}$ Q. Zhang, H. Kuwabara, W.J. Potscavage, S. Huang, Y. Hatae, T. Shibata, and C. Adachi, J. Am. Chem. Soc. 136, 18070 (2014).

102 T. Takahashi, K. Shizu, T. Yasuda, K. Togashi, and C. Adachi, Sci. Technol. Adv. Mater. 15, (2014).

${ }^{103}$ S. Wang, X. Yan, Z. Cheng, H. Zhang, Y. Liu, and Y. Wang, Angew. Chemie 127, 13260 (2015).

104 Q. Zhang, B. Li, S. Huang, H. Nomura, H. Tanaka, and C. Adachi, Nat. Photonics 8, 326 (2014).

${ }^{105}$ S.Y. Lee, T. Yasuda, Y.S. Yang, Q. Zhang, and C. Adachi, Angew. Chemie - Int. Ed. 53, 6402 (2014).

${ }^{106}$ Y. Kitamoto, T. Namikawa, D. Ikemizu, Y. Miyata, T. Suzuki, H. Kita, T. Sato, and S. Oi, J. Mater. Chem. C 3, 9122 (2015).

${ }^{107}$ W.L. Tsai, M.H. Huang, W.K. Lee, Y.J. Hsu, K.C. Pan, Y.H. Huang, H.C. Ting, M. Sarma, Y.Y. Ho, H.C. Hu, C.C. Chen, M.T. Lee, K.T. Wong, and C.C. Wu, Chem. Commun. 51, 13662 (2015).

108 H. Uoyama, K. Goushi, K. Shizu, H. Nomura, and C. Adachi, Nature 492, 234 (2012).

${ }^{109}$ S. Huang, Q. Zhang, Y. Shiota, T. Nakagawa, K. Kuwabara, K. Yoshizawa, and C. Adachi, J. Chem. Theory Comput. 9, 3872 (2013).

110 P.K. Samanta, D. Kim, V. Coropceanu, and J.L. Brédas, J. Am. Chem. Soc. 139, 4042 (2017).

111 J. Gibson and T.J. Penfold, Phys. Chem. Chem. Phys. 19, 8428 (2017).

112 C.M. Marian, J. Phys. Chem. C 120, 3715 (2016).

113 J. Gibson, A.P. Monkman, and T.J. Penfold,

ChemPhysChem 2956 (2016).

114 T. Etienne, H. Gattuso, C. Michaux, A. Monari, X. Assfeld, and E.A. Perpète, Theor. Chem. Acc. 135, 1 (2016). 